\title{
El feminicidio como tipo penal autónomo
}

Rebeca Elizabeth Contreras López*

El feminicidio es el homicidio de una o más mujeres que son privadas de la vida por ser mujeres, aunque el tema es abundante y requiere abordajes diversos; en este comentario la finalidad concreta es establecer los elementos dogmático-penales del feminicidio y poner en la mesa de discusión las distintas problemáticas que conlleva. La reflexión parte de distintas opciones para su regulación: a). Como tipo penal autónomo, que es el que sigue el Código Penal de Veracruz; b). Como una modalidad específica del homicidio, que recoge el Código Penal federal; c). Como una agravante. También su ubicación sistemática puede variar: en delitos contra la vida y la salud; en delitos de violencia de género o, incluso, dentro de los delitos de violencia familiar, en una visión mucho más restringida.

Es necesario distinguir los fines de la tipificación de las conductas punibles: a) Protección de bienes jurídicos, b) Sancionar conductas intolerables para la vida en sociedad y, paralelamente, c) Prevenir que esas conductas se repitan. Esta última es consecuencia de que las autoridades actúen en forma eficiente y apegada a la ley, pero de ninguna manera puede ser la única función de la ley penal, ya que entonces se desvirtúan los fines del derecho y se suplanta la función administrativa de gestionar políticas y programas públicos para lograr estos fines. Sin duda, es importante que se visibilice la violencia contra las mujeres y que se sancione a quienes la realizan, porque resulta aberrante la realización de conductas que conllevan la privación de la vida de una persona. Aunque, desde un análisis dogmático penal también hay que tomar en cuenta que la sobrerregulación en lugar de eficientar a la justicia penal la hace incierta, compleja y, en muchas ocasiones, ineficiente.

La legislación que ocuparé será la penal tanto federal, como del estado de Veracruz. Así encontramos que el Código Penal Federal, en su artículo 325, dentro de los tipos penales contra la vida y la integridad, corporal tipifica al feminicidio como tipo autónomo de homicidio, de la forma siguiente (el resaltado es mío):

Comete el delito de feminicidio quien prive de la vida a una mujer por razones de género. Se considera que existen razones de género cuando concurra alguna de las siguientes circunstancias:

I.La víctima presente signos de violencia sexual de cualquier tipo;

II.A la víctima se le hayan infligido lesiones o mutilaciones infamantes o degradantes, previas o posteriores a la privación de la vida o actos de necrofilia;

III.Existan antecedentes o datos de cualquier tipo de violencia en el ámbito familiar, laboral o escolar, del sujeto activo en contra de la víctima;

IV.Haya existido entre el activo y la víctima una relación sentimental, afectiva o de confianza;

V.Existan datos que establezcan que hubo amenazas relacionadas con el hecho delictuoso, acoso

* Investigadora nacional, nivel 1. Adscrita al Centro de Estudios sobre Derecho, Globalización y Seguridad de la Universidad Veracruzana. Profesora de Derecho Penal, política criminal y metodología de la investigación en Licenciatura y posgrado. 
o lesiones del sujeto activo en contra de la víctima;

VI.La víctima haya sido incomunicada, cualquiera que sea el tiempo previo a la privación de la vida;

VII.El cuerpo de la víctima sea expuesto o exhibido en un lugar público.

A quien cometa el delito de feminicidio se le impondrán de cuarenta a sesenta años de prisión y de quinientos a mil días multa.

Además de las sanciones descritas en el presente artículo, el sujeto activo perderá todos los derechos con relación a la víctima, incluidos los de carácter sucesorio.

En caso de que no se acredite el feminicidio, se aplicarán las reglas del homicidio.

Por su parte, en el Código Penal de Veracruz, artículo 367 bis, dentro de los delitos de violencia de género se establece el tipo penal de feminicidio (similar al federal), de la siguiente forma:

Comete el delito de feminicidio quien por razones de género priva de la vida a una mujer. Existen razones de género cuando se presenta alguna de las siguientes circunstancias:

I. Exista o haya existido entre el activo y la víctima una relación de parentesco por consanguinidad o afinidad, de matrimonio, concubinato, noviazgo o cualquier otra relación de hecho o amistad;

II. Exista o haya existido entre el activo y la víctima una relación laboral, escolar, o cualquier otra que implique confianza, subordinación o superioridad;

II. Bis. El activo se haya valido de su relación como conductor de un vehículo de transporte de pasajeros, turismo o cualquier otra modalidad;

III. La víctima presente signos de violencia sexual de cualquier tipo;

IV. A la víctima se le hayan infligido lesiones infamantes, degradantes o mutilaciones previamente a la privación de la vida, o se realicen marcas infamantes o degradantes sobre el cadáver, o éste sea mutilado;

V. Hayan existido amenazas, acoso o lesiones del sujeto activo en contra de la víctima; VI. El cuerpo de la víctima sea expuesto o arrojado en un lugar público; o

VII. La víctima haya sido incomunicada.

A quien cometa el delito de feminicidio se le impondrá una sanción de cuarenta a setenta años de prisión. Además de la sanción descrita en el presente artículo, el imputado perderá todos los derechos con relación a la víctima. Para el supuesto de la fracción I perderá también los derechos de familia y los de carácter sucesorio.

En la configuración del delito, no es necesario que se acredite la personalidad misógina del inculpado.

Existen diversas problemáticas evidentes en estas formas de tipificación:

1. La ubicación sistemática del tipo penal.

2. El bien jurídico protegido.

3. La configuración del tipo subjetivo a partir de circunstancias materiales y no de la determinación de la conducta dolosa del sujeto activo.

\section{Ubicación sistemática}

Resulta más adecuada la decisión del legislador federal, al ubicar al feminicidio como una forma de homicidio, ya que deja la posibilidad de sancionar por homicidio cuando no se logra demostrar el tipo objetivo y subjetivo del feminicidio. En el caso de Veracruz, ello no es posible, ya que si no se demuestra el tipo penal se corre el riesgo de dejar impune la conducta, ya que se trata de un tipo penal independiente, en el que sin embargo se determina la integración de un tipo penal de privación de la vida similar al homicidio, en caso de absolver por feminicidio, ya no se podría juzgar por homicidio, ya que son tipos 
independientes pero referidos a la misma conducta (De acuerdo al artículo 23 de la Constitución federal, nadie puede ser juzgado dos veces por el mismo delito).

Por tanto, lo más acertado es considerar al feminicidio como un tipo especial, derivado del tipo básico de homicidio, cuya razón de su regulación obedece a una necesidad evidente de frenar cualquier forma de violencia contra las mujeres, tal como lo ordenó la CIDH en repetidas ocasiones. Así se señala en la siguiente tesis jurisprudencial:

FEMINICIDIO. ACCIONES IMPLEMENTADAS PARA COMBATIRLO EN ATENCIÓN A LAS RECOMENDACIONES DE LA CORTE INTERAMERICANA DE DERECHOS HUMANOS EN LA SENTENCIA DICTADA EN EL CASO GONZÁLEZ Y OTRAS (CAMPO ALGODONERO) VS. MÉXICO (LEGISLACIÓN DEL ESTADO DE JALISCO).

La Corte Interamericana de Derechos Humanos (CIDH), atento a los sucesos de violencia contra las mujeres por razones de género; como consecuencia de una situación estructurada y de fenómenos sociológicos y culturales arraigados en un contexto social de violencia y discriminación basado en el género, y al considerar el delito de homicidio contra la mujer (feminicidio) como la forma extrema de violencia de género, el 16 de noviembre de 2009, dictó sentencia en el caso González y otras (campo algodonero) vs. México, y en su apartado 4, denominado: "Medidas de satisfacción y garantías de no repetición" señaló, como parte de dichas garantías, que los Estados deben llevar a cabo la "Estandarización de los protocolos, criterios ministeriales de investigación, servicios periciales y de impartición de justicia, para combatir desapariciones y homicidios de mujeres y los distintos tipos de violencia contra las mujeres". En ese sentido, el Estado Mexicano y, en específico, el Estado de Jalisco, incluyó en el artículo 232-Bis de su Código Penal, el delito de feminicidio, en el que se establece que si bien éste deriva del tipo básico del homicidio y participa de algunos de sus elementos esenciales, verbigracia, privar de la vida a una persona, añade otros, como el que esa conducta sea cometida contra una mujer por razones de género, odio, misoginia, etcétera; de igual forma, el 14 de noviembre de 2012, se emitió "El Protocolo de Investigación del Delito de Feminicidio con perspectiva de género para el Estado de Jalisco" (vigente a partir del 21 siguiente), en el que se establecen los parámetros y procedimientos de investigación que deben llevarse a cabo ante todo caso de muertes de mujeres, incluidas aquellas que, prima facie, parecerían haber sido causadas por motivos criminales, suicidio y algunos accidentes, y que deben analizarse con perspectiva de género, para determinar si hubo o no razones de género en la causa de la muerte y confirmar o descartar el motivo del deceso, de conformidad con el artículo 133-Bis del Código de Procedimientos Penales para el Estado. SEGUNDO TRIBUNAL COLEGIADO EN MATERIA PENAL DEL TERCER CIRCUITO.

\section{El bien jurídico protegido}

En el análisis dogmático penal un aspecto sustancial es la determinación del bien jurídico que cada tipo penal protege, ya que se refiere al objeto de protección de la norma que permite realizar una interpretación más adecuada de los distintos elementos del tipo penal. Es, además, el fin del Derecho Penal, dado que lo esperado es que cada tipo penal efectivamente sea protector de bienes jurídicos y no meros mandatos administrativos que impliquen sólo "la amenaza de la pena", sin una ulterior finalidad de tutela de los derechos fundamentales de los ciudadanos. 
Una finalidad sistemática, en el análisis del bien jurídico, es su ubicación en el conjunto de tipos penales que establecen los códigos punitivos y que, a su vez, ayudan a resolver algunas problemáticas específicas como el concurso de delitos o la calificativa de ciertas conductas sin vulenerar derechos y garantías procesales y sustantivas.

El bien jurídico protegido es sin duda la vida de las mujeres, por tanto, la decisión del legislador veracruzano de ubicar esta figura típica en delitos de violencia de género, lo único que logra es mermar las posibilidades de análisis y punición de estos hechos delictivos, dado que minimiza la gravedad de la conducta, al obviar la importancia de la vida como bien jurídico primario y esencial. Nuevamente, la mejor opción es ubicarlo en delitos contra la vida y la integridad corporal.

\section{Configuración del tipo subjetivo}

En este aspecto, ambas legislaciones tienen la misma problemática. En el tipo penal se establece que comete feminicidio "quien por razones de género priva de la vida a una mujer", lo que implica que sus elementos típicos objetivos son: a) Existencia previa de una vida humana, b) Que esa vida sea la de una mujer y c) La extinción de esa vida física por parte de un tercero.

Ahora bien, el problema principal se presenta en el aspecto subjetivo del tipo, ya que sin duda se trata de una conducta que debe realizarse en forma dolosa, es decir, con intención; sin embargo, esa intención de privar de la vida a una mujer debe realizarse "por razones de género". ¿Qué significan las razones de género en el tipo penal? En términos generales podemos decir que el desprecio, el odio, el desdén por las mujeres, que debe manifestarse en la intencionalidad, en la parte subjetiva, emocional, del sujeto activo (del agresor). Para Incháustegi, las razones de género, se ubican en:

...el marco de la dominación masculina orientada por el deseo sexual y de control sobre el cuerpo y la libertad de las mujeres. E identifica la complicidad del orden legal del Estado y de otras instituciones hegemónicas (medios de comunicación, cosmovisiones religiosas) que lo disimulan, toleran, justifican o incluso atenúan su gravedad mediante la prevalencia de legislaciones penales que justifican estos crímenes... (2014: 373).

Consideremos dos aclaraciones: a). Las razones de género no sólo se refieren a la mujer, sino a cualquier situación en donde se sigan estereotipos de género, sin importar el sexo de la víctima. b). Los elementos subjetivos del tipo se refiere a la voluntad, la subjetividad del sujeto activo, ya que la responsabilidad penal es por naturaleza subjetiva, no objetiva, y sólo se configura por dolo o culpa; por tanto, no se puede demostrar una intencionalidad con elementos objetivos como los que este tipo penal plantea.

Para establecer las razones de género, el tipo penal, recoge circunstancias objetivas, es decir, concretas, materiales, que dejan de lado la intencionalidad del sujeto activo, lo que de suyo constituye una violación directa a la configuración de la responsabilidad penal y el debido proceso. Así encontramos un listado de circunstancias, antes señaladas, que dan por sentado que el hecho ha ocurrido por "razones de género", cuando esas "razones" deben pasar primero por la mente del agresor, pero el legislador ha querido disminuir la carga probatoria para que en el proceso sea "más fácil" la persecusión y juzgamiento de estas 
conductas. Lo cierto es que dicha regulación en lugar de beneficiar a la justicia y proteger a las víctimas hace aún más compleja la demostración del tipo penal.

Si bien, cada una de las circunstancias de esta enumeración remiten a condiciones objetivas del tipo penal, que deben ser demostradas con pruebas directas que permitan comprobar alguna de ellas, sin duda sigue siendo imprescindible que se analice el tipo subjetivo, es decir, la existencia del dolo, conformado por los elementos cognitivo y volitivo, es decir, conocimiento y voluntad de lo que se hace. Primero, conocimiento de que se realiza una conducta antijurídica, en este caso la privación de la vida de una mujer, y segundo, la voluntad, el deseo, de privarla de la vida "por razones de género", porque siente odio, rechazo o menosprecio por ella o por el género femenino en su conjunto, porque asume que las mujeres son inferiores o carecen incluso de dignidad humana. Un sentimiento que por cierto no únicamente pueden sentir los hombres, de ahí que es correcto en este sentido la tipificación del feminicidio cuando no exige un sexo específico para el agresor.

Dadas las limitaciones de este comentario, únicamente se establecen líneas de discusión que son relevantes respecto a la tipificación de esta figura y su aplicación en los procedimientos penales, ya que muchas veces, a partir de la propia ubicación sistemática en los códigos se tienen que tomar decisiones en sede jurisdiccional que, no siempre son las esperadas por la sociedad y ni siquiera fueron consideradas por el legislados que, en su afán por cumplir con los reclamos sociales, realiza legislaciones apresuaradas e irreflexivas que en lugar de proteger, entorpecen la función de procuración y administración de la justicia penal.

\section{Fuentes consultadas:}

Constitución Política de los Estados Unidos Mexicanos.

\section{Código Penal Federal.}

Código Penal del estado libre y soberano de Veracruz.

FEMINICIDIO. ACCIONES IMPLEMENTADAS PARA COMBATIRLO EN ATENCIÓN A LAS RECOMENDACIONES DE LA CORTE INTERAMERICANA DE DERECHOS HUMANOS EN LA SENTENCIA DICTADA EN EL CASO GONZÁLEZ Y OTRAS (CAMPO ALGODONERO) VS. MÉXICO (LEGISLACIÓN DEL ESTADO DE JALISCO). Registro 2009891, Tesis: III.2o.P.83 P (10a.), Gaceta del Semanario Judicial de la Federación, 10ạ época.

Icháustegi Romero, Teresa (2014). Sociología y política del feminicidio; algunas claves interpretativas a partir del caso mexicano. En Revista Sociedad y estado. Vol.29 No.2. Brasilia mayo/agosto 2014, pp. 373 a 400. DOI: https://doi.org/10.1590/S010269922014000200004 